\title{
Competências inferenciais e linguísticas na compreensão de textos narrativos
}

\author{
por alunos surdos
}

\section{Deaf students' linguistic skills in understanding narrative texts and implicit}

\section{language}

\author{
Raquel Castro, Filomena Ponte \\ FF/CS/UCP - Braga, Portugal
}

\begin{abstract}
Resumo
Considerando que a nossa relação com o mundo está intimamente ligada com a forma como o percebemos, importa descortinar como as crianças surdas interpretam aquilo que leem. Assim, considerou-se necessário contribuir para a perceção das aptidões desses alunos na compreensão de textos narrativos com alguma complexidade ao nível da estrutura e da linguagem, principalmente na perspetiva imaterial e semântica de uma língua, a partir da sua leitura, determinando se estes alunos ativam os mecanismos necessários para a compreensão e apreensão adequada desses conteúdos, nomeadamente na antecipação, dedução ou inferência de conteúdos de um texto literário.

Palavras-chave: surdez, leitura, linguagem conotativa
\end{abstract}

\begin{abstract}
Considering that our relationship with the world is intimately connected with the way in which we perceive it, it is important to understand how children with hearing impairment interpret what they read. Thus, it was considered necessary to fully perceive those students' reading skills in understanding narrative texts with complex structures and language, mainly from the incorporeal, semantic and intangible perspective of a language, determining whether these students activate the necessary mechanisms to the proper apprehension of those contents, particularly by anticipating, deducting or inferring the contents of a literary text.

Keywords: deafness, reading, connotative language
\end{abstract}

\section{Introdução}

As constantes alterações na Lei de Bases do Sistema Educativo e nas políticas e orientações do Ministério da Educação, fundamentadas em projetos de investigação de diversas origens, para o Ensino Básico e para o Ensino Secundário dos alunos surdos, das quais salientamos o Decreto-lei n. ${ }^{\circ} 3 / 2008$, a recente proposta de alteração a esse decreto, a elaboração dos programas de Língua Gestual Portuguesa (LGP) e de Português Língua Segunda (L2) consolidam a importância da compreensão das especificidades das crianças e jovens com deficiência auditiva.

Cientes de que a forma como nos relacionamos e interagimos com o mundo está intimamente ligada com a forma como o percecionamos, a ausência parcial ou integral de um dos recursos que o ser humano dispõe para esse efeito poderá implicar o reajuste e o reforço de outras faculdades e capacidades. Assim sendo, a perda de audição interfere diretamente no modo como comunicamos/interagimos, assim como na forma como acedemos à informação.

Neste contexto de multiplicidade de relacionamentos interpessoais, surgiu o interesse de analisar de que forma as crianças detentoras de um determinado grau de surdez interpretam aquilo que leem, para, a partir daí, construírem conhecimento. Interessa, sobretudo, o processo inerente à compreensão de mensagens escritas e a diversidade de (pré)requisitos que este processo poderá acarretar, sem, no entanto, ignorar as especificidades linguísticas dos alunos com surdez, as quais estão diretamente associadas com a sua severidade, o momento da perda auditiva, as características do meio de socialização primário, familiar, social e escolar. De facto, "a surdez per si não será impeditiva do desenvolvimento integral do indivíduo, se este tiver acesso ao desenvolvimento do seu pensamento, onde a linguagem surge como motor do mesmo. A aquisição da linguagem na criança surda será plena através da via visual (...). Assim, se toda a informação e conhecimento forem transmitidos de forma visual, através da língua gestual ou da Língua Portuguesa escrita e eventualmente falada (se bem aprendida e estruturada), o surdo terá acesso a todo tipo de aprendizagens a que tem direito $e$ a surdez terá adquirido outro significado, o de uma diferença linguística e cultural que se quer reconhecida e dignificada" (Revista Diversidades, 2009, p. 5).

$\mathrm{O}$ ato de ler desempenha um papel de importância primordial para o ser humano, pois é a sua fonte de socialização, de integração, de acesso à informação e ao conhecimento, principalmente para aqueles que se veem privados do acesso por via auditiva. De facto, citando Inês Sim-Sim, é através da leitura que o "leitor acede ao que até aí era para si desconhecido, inexistente ou irrelevante, sendo a leitura uma alavanca determinante no percurso do desenvolvimento pessoal. Saber ler é, por isso, fulcral e o desenvolvimento gnósico ganha 
contornos especiais quando o lido tem cariz linguístico" (Viana, 2002, p.5). Aliás, de acordo com a mesma autora, "parafraseando Goethe, a aprendizagem da leitura é uma tarefa para a vida inteira” (idem), pois é um processo complexo que exige motivação, vontade, esforço, e que mobiliza uma diversidade de capacidades, não se limitando à mera descodificação alfabética. $O$ conceito de leitura encerra uma multiplicidade de competências, de mecanismos mentais de descodificação e compreensão e deve ser encarado como um processo gradual e dinâmico.

Conscientes de que a surdez compromete o desenvolvimento da linguagem oral e de que a escrita é uma representação do oral, muitos estudos referem o baixo nível de desempenho dos alunos surdos na leitura, comparativamente ao dos alunos ouvintes, pois o conhecimento restrito ou a completa ausência do conhecimento da dimensão oral da língua, interfere no domínio da leitura e da escrita (Reis, 2002, p. 4), sem ignorar o facto de que, no caso da maioria dos alunos surdos, não há correspondência entre a primeira língua (L1) e a língua de escolarização. A este respeito, Luísa Lourenço explica que as "dificuldades que os alunos surdos apresentam ao nível da compreensão da leitura devem-se, fundamentalmente, a condicionalismos que advêm do facto de a língua escrita portuguesa funcionar para estes alunos como uma segunda língua" (Sim-Sim, 2005, p. 49). De modo que implicará a prevalência de alguns problemas no âmbito da leitura, tais como a pouca diversidade de vocabulário, o fraco conhecimento da estrutura sintática do Português, o "desconhecimento dos diversos níveis de estruturação dos textos e a consequente falta de preparação para os tratar" (idem). Além destas causas, é necessário ter em consideração outros fatores que influenciam a capacidade de compreensão de registos escritos por parte da população surda, de entre as quais "salienta-se a falta de conceitos adequados para relacionar com o novo conteúdo a ler (ou dificuldades em os activar), a falta de atenção que impede o aluno de se concentrar no que é essencial e reconhecer o acessório, a dificuldade de interacção do aluno com o texto e as dificuldades na autogestão da aprendizagem, devida a um baixo desenvolvimento das suas capacidades metacognitivas" (idem).

Não pretendemos, no entanto, analisar as estratégias utilizadas por estes alunos no processo de leitura, mas sim depreender até que ponto as dificuldades de aquisição da leitura apontadas em diversos estudos interferem na compreensão de determinado tipo de mensagens escritas, principalmente de cariz inferencial e plurissignificativo, a partir de elementos paratextuais, contextuais e de marcadores discursivos.

\section{Método}

Tendo em conta os objetivos delineados e o facto de se tratar de uma investigação em educação, seguimos os paradigmas de investigação qualitativa e quantitativa, ou seja, uma metodologia mista com a possibilidade de prevalência de um ou de outro método em maior grau, recorrendo, então, a objetivos visados por cada uma delas, nomeadamente na recolha e tratamento de dados, como o recurso a instrumentos de observação passiveis de mensuração (questionário estruturado e de respostas fechadas) e a consequente análise estatística, para, a partir da análise dos mesmos, efetuar uma análise interpretativa do seu conteúdo e compreender uma determinada tendência ou fenómeno educativo, focalizando as especificidades e características evidenciadas pelo grupo social estudado (Morais \& Neves, 2007).

\section{Amostra}

A amostra definida enquadra-se nas designadas amostras não-probabilísticas por conveniência, uma vez que este tipo de amostragem é constituído por um conjunto de elementos facilmente analisáveis e disponíveis, não sendo por definição representativa de uma população, e, como tal, o número de participantes não foi previamente estabelecido. Com efeito, mediante os objetivos da investigação que pretendem auferir as competências de literacia, estes participantes teriam que ser detentores de determinadas características, nomeadamente possuir um determinado grau de surdez, independentemente da sua etiologia, frequentar o segundo ou o terceiro ciclo do ensino básico e, consequentemente, deter alguma fluência leitora.

Neste estudo, em concreto, optamos por incidir a nossa investigação numa escola de referência de um distrito do Norte de Portugal, uma vez que reúne um número significativo de alunos com diferentes graus de surdez, nos diversos níveis de ensino e com modelos pedagógicos diferenciados, perfazendo uma amostragem composta por 22 alunos $(\mathrm{n}=22)$ dos segundo e terceiro ciclos, distribuídos de acordo com a tabela 1 .

Tabela 1

Distribuição da amostragem por anos de escolaridade.

\begin{tabular}{ccc}
\hline $\begin{array}{c}\text { Ano de } \\
\text { escolaridade }\end{array}$ & Frequência & Percentagem \\
\hline $5 .^{\circ}$ & 3 & 13.64 \\
$6 .^{\circ}$ & 6 & 27.27 \\
$7 .^{\circ}$ & 6 & 27.27 \\
$8 .^{\circ}$ & 3 & 13.64 \\
$9 .^{\circ}$ & 4 & 18.18 \\
Total & 22 & 100.0 \\
\hline
\end{tabular}

De acordo com os ciclos de ensino, as idades dos participantes oscilam entre os 11 e os 17 anos, dos quais $13(n=13)$ pertencem ao sexo masculino e $9(n=9)$ ao sexo feminino (ver Figura 1).

| 11 anos $=12$ anos $=13$ anos $\mid=14$ anos $\mid=15$ anos $\| 16$ anos $=17$ anos

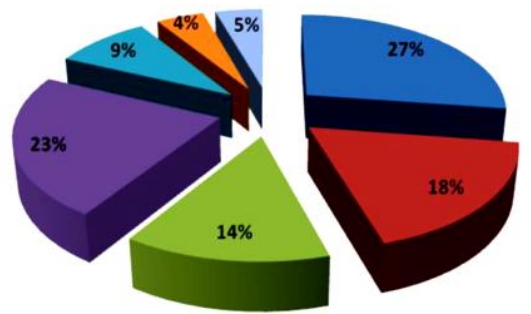

Figura 1. Distribuição dos participantes por idade 
Relativamente ao grau de surdez, deve considerar-se o facto de metade dos participantes serem detentores de surdez profunda ou severa e apenas uma pequena percentagem possuir surdez moderada ou mista. Além disso, $73 \%$ dos alunos surdos adotou como L1 a LGP em detrimento da LP1, seguindo, assim, a modalidade bilingue de ensino, ou seja, a bordagem que atualmente é considerada como sendo a mais proficiente para a educação destes alunos. Com efeito, a segunda língua (L2) da maioria dos alunos (73\%) é a Língua Portuguesa e, como tal, apenas $14 \%$ dos participantes optou pela LGP2 e 13\% pela Língua Inglesa.

\section{Instrumentos e procedimentos}

Pelo exposto, na fase da elaboração dos instrumentos de obervação, optou-se pela recolha de informação efetuada indiretamente, através da aplicação de questionários, para a partir daí obter alguns indicadores. Assim, para se avaliar o desempenho dos alunos na compreensão da leitura, efetuamos um questionário fechado, constituído po perguntas de escolha múltipla e de ordenação de sequências narrativas, cujas respostas seriam fornecidas após a leitura individualizada e/ou apoiada por um intérprete de LGP de um texto narrativo, cuja extensão e grau de difcudade alterariam mediante o ciclo de ensino do público-alvo e que não deveriam ser do seu conhecimento e plano de estudos. A escolha da tipologia textual prendeu-se, essencialmente, com os dados obtidos na revisão da literatura, os descritores de desempenho definidos no programa da L2 e com o facto de este algutinar no conteúdo, na estrutura e nas relações semânticas as características que serviriam o propósito do nosso estudo, nomeadamente a presença de recursos expressivos, vocabulário semanticamente diversificado, marcadores discursivos e de outros elementos de coerência e coesão textual.

Os instrumentos elaborados obedeceram a uma estrutura tripartida, em que o primeiro momento abarcou exercícios de pré-leitura/de antecipação de sentidos (análise de elementos paratextuais), o segundo momento acarretou a leitura do texto narrativo e o último implicou a resolução de um questionário representativo da compreensão do texto lido, o qual foi subdividido numa parte de compreensão global do sentido do texto e noutra de compreensão de cada uma das partes que o compõem. Tendo em conta a carga letiva máxima definida para as diferentes disciplinas, embora não tenha sido determinado um tempo limite para a execução destas tarefas, estas foram concebidas para um máximo de noventa minutos.

Após a definição e a elaboração dos instrumentos, foram assegurados todos os procedimentos éticos intrínsecos a todos os processos de investigação, com o intutito de se assegurar os direitos de todos os intervenientes e de minimizar os impactos da aplicação desses instrumentos. Posto isto, a recolha de dados foi efetuada no contexto natural de escolarização dos participantes e, preferencialmente, dentro do seu horário letivo.

Recorrendo ao auxílio dos intérpretes e dos professores, orientámos os alunos no preenchimento do questionário, de acordo com os objetivos pretendidos e as etapas referidas anteriormente. Durante a execução das tarefas propostas, embora alguns alunos tenham recorrido ao intérprete para traduzir para LGP passagens do texto escrito, na maioria dos casos este auxília foi usado como elemento facilitador da comunicação entre o aluno e o investigador, principalmente durante a explicação das intruções.

Para a recolha de dados, foram elaborados instrumentos de análise quantitativa e qualitativa das respostas fornecidas pelos alunos. Após a análise aluno a aluno das respostas, elaborou-se uma tabela de análise global por ciclo, que permitisse contabilizar o número de respostas Adequadas, Pouco Adequadas ou Inadequadas obtidas em cada item, permitindo uma contabilização dos dados por pergunta e pelas etapas do processo de leitura (pré-leitura, compreensão global, compreensão específica de determinados segmentos). Com o intuito de contribuir para uma perspetiva qualitativa do domínio de competências de literacia pelos alunos surdos, agrupamos os itens por parâmetros de análise, tendo como pano de fundo alguns dos descritores de desempenho do programa de Português (L2). Assim, os itens do questionário de escolha múltipla foram agrupados seguindo os critérios subsequentes, de acordo com os objetivos da investigação: interpretar elementos paratextuais, para inferir sentidos (parâmetro A); inferir significados implícitos em passagens textuais e em vocabulário plurissignificativo ou polissémico (parâmetro B); localização de informação no texto e organização de sequências textuais a partir de elementos de coerência (marcadores discursivos) e coesão textual (parâmetro C).

\section{Apresentação e discussão dos resultados}

Apresentamos os resultados mediante os procedimentos e as etapas anteriormente descritas, com o intuito de elaborar inferências plausíveis da amostra selecionada para o nosso estudo, os quais foram organizados da seguinte forma: (i) resultados do segundo ciclo do ensino básico; (ii) resultados do terceiro ciclo do ensino básico; (iii) resultados contrastivos dos segundo e terceiro ciclos do ensino básico, para a partir desta comparação tirar algumas conclusões.

No geral, os dois anos de escolaridade que constituem o segundo ciclo do ensino básico (5..$^{\circ}$ e $6 .^{\circ}$ anos) obtiveram valores percentuais de "Adequados", "Pouco Adequados" e "Inadequados" muito próximos entre si, posicionando o seu desempenho num patamar positivo, embora estes não sejam significativos, uma vez que o número de itens com respostas pouco adequadas e inadequadas aproximam-se do número de itens adequados, ou seja, atingem os $48.24 \%$ e $47.7 \%$, no $5 .^{\circ}$ e no $6 .^{\circ}$ ano, respetivamente. No que concerne a aferição qualitativa efetuada a partir da análise pelos parâmetros referidos anteriormente (A, B, e C), apresentamos, no quadro que se segue, o desempenho desses alunos em cada um deles (ver Tabela 2). 
Tabela 2

Resultados obtidos pelos participantes do $2 .^{\circ} \mathrm{CEB}$ nos parâmetros de avaliação da leitura

\begin{tabular}{ccccc} 
& \multirow{2}{*}{ Parâmetros } & \multicolumn{3}{c}{ Número de ocorrências } \\
\cline { 3 - 5 } & & $\mathrm{A}$ & $\mathrm{P} / \mathrm{A}$ & $\mathrm{I}$ \\
\hline \multirow{2}{*}{$5 .^{\circ}$} & $\mathrm{A}$ & $63 \%$ & $25 \%$ & $13 \%$ \\
ano & $\mathrm{B}$ & $34 \%$ & $31 \%$ & $34 \%$ \\
& $\mathrm{C}$ & $61 \%$ & $28 \%$ & $11 \%$ \\
\hline \multirow{2}{*}{$6 .^{\circ}$} & $\mathrm{A}$ & $40 \%$ & $60 \%$ & $0 \%$ \\
ano & $\mathrm{B}$ & $55 \%$ & $15 \%$ & $30 \%$ \\
& $\mathrm{C}$ & $53 \%$ & $24 \%$ & $24 \%$ \\
\hline
\end{tabular}

A partir da análise da tabela é possível constatar que, em ambos os anos de escolaridade, os alunos revelaram mais dificuldades nos itens que exigiam a descodificação de mensagens implícitas e de vocabulário cujo significado só se poderia obter através de uma compreensão contextualizada (parâmetro B), de acordo com os descritores de desempenho que preveem a descodificação, pelo contexto ou pelo recurso a obras lexicográficas diversas, o sentido de palavras ou expressões desconhecidas e a captação de sentidos implícitos, a execução de inferências e deduções (ME/DGIDC, p. 63, 2011). Podendo isto significar que os alunos do $6^{\circ}$ ano, tal como seria de prever, adquiriram mais competências ao nível da compreensão e que, embora possam ter mais anos com a LGP como L1, esta não terá tido repercussões na aquisição de aptidões de descodificação sintática e semântica.

Não obstante as constatações anteriores, contrariamente ao sucedido no $6 .^{\circ}$ ano, os alunos que constituíam o grupo referente ao $5 .^{\circ}$ ano revelaram menos dificuldades na resolução dos itens respeitantes ao parâmetro C, evidenciando algum domínio na localização de informação no texto e na organização de sequências textuais a partir dos elementos de coerência e de coesão textual. Não obliterando a possibilidade de coexistirem fatores de índole motivacional, estes dados poderão indiciar também uma maior capacidade na apreensão global do texto, encarando-o como a sucessão lógica de sequências, a partir do reconhecimento explícito ou implícito da utilização correlativa de tempos verbais, de advérbios ou locuções adverbais de localização temporal, de conetores, entre outros elementos estruturantes de um texto. Assim, tal como está previsto no Programa de Português L2, estes alunos evidenciaram saber "utilizar estratégias diversificadas para procurar a informação num texto, activando a leitura global, selectiva ou analítica em função do objectivo de leitura" (ME/DGIDC, p. 62, 2011), com a agravante de que os exercícios incidiam na localização de informação menos evidente, não obedecendo ao pressuposto referido no mesmo programa de que os textos devem privilegiar o uso de uma linguagem corrente.

Além disso, a partir da análise do quadro, salientamos também que, devido à inexistência de qualquer resposta "inadequada", o 6. ano de escolaridade revelou um bom desempenho na resolução dos itens que implicavam a inferência de dados sobre o texto, a partir da análise dos elementos paratextuais apresentados, de acordo com os seguintes descritores de desempenho do Programa de Português L2: "Procurar no texto elou na sua ilustração a resposta a questões colocadas"; "Mobilizar informação armazenada, investindo-a na antecipação, compreensão e construção de novo conhecimento"; "Apreciar aspectos materiais e paratextuais do livro" (ME/DGIDC, p. 62, 2011).

Foram adotados os mesmos procedimentos para a análise dos resultados obtidos com os participantes do $3 .^{\circ}$ ciclo do ensino básico. Constatou-se que o número de respostas consideradas "adequadas" não atingiu os $50 \%$ em todos os níveis de ensino do $3 .^{\circ}$ ciclo. No entanto, tendo em consideração que foi aplicado o mesmo questionário aos $7 .^{\circ}, 8 .^{\circ}$ e $9 .^{\circ}$ anos, denota-se um ligeiro progresso na percentagem de respostas adequadas à medida que se avança no ano de escolaridade, a saber: $34.85 \%$, $40.91 \%$ e $48.86 \%$, respetivamente. Consequentemente, a percentagem mais elevada de respostas "inadequadas" ocorreu no $7 .^{\circ}$ ano, tal como seria esperado. $\mathrm{Na}$ análise por parâmetros, observou-se, na tabela 3, o seguinte:

Tabela 3

Resultados obtidos pelos participantes do 3. ${ }^{\circ}$ CEB nos parâmetros de avaliação da leitura.

\begin{tabular}{ccccc} 
& \multirow{2}{*}{ Parâmetros } & \multicolumn{3}{c}{ Número de ocorrências } \\
\cline { 3 - 5 } & & A & P/A & I \\
\hline \multirow{2}{*}{$7 .^{\circ}$} & $\mathrm{A}$ & $67 \%$ & $33 \%$ & $0 \%$ \\
ano & $\mathrm{B}$ & $13 \%$ & $35 \%$ & $52 \%$ \\
& $\mathrm{C}$ & $47 \%$ & $11 \%$ & $42 \%$ \\
\hline \multirow{2}{*}{$8 .{ }^{\circ}$} & $\mathrm{A}$ & $67 \%$ & $33 \%$ & $0 \%$ \\
ano & $\mathrm{B}$ & $26 \%$ & $41 \%$ & $33 \%$ \\
& $\mathrm{C}$ & $48 \%$ & $6 \%$ & $45 \%$ \\
\multirow{2}{*}{$9{ }^{\circ}$} & $\mathrm{A}$ & $63 \%$ & $38 \%$ & $0 \%$ \\
ano & $\mathrm{B}$ & $47 \%$ & $31 \%$ & $22 \%$ \\
& $\mathrm{C}$ & $48 \%$ & $18 \%$ & $34 \%$ \\
\hline
\end{tabular}

Constatamos que os alunos dos três níveis de ensino obtiveram melhores resultados na resolução dos itens de pré-leitura, ou seja, no parâmetro A, sustentando, assim, a capacidade dos alunos em efetuar inferências/deduções plausíveis e em efetuar hipóteses de leitura válidas, tal como está previsto no Programa de L2.

Estando cientes da complexidade do texto escolhido, principalmente no que concerne ao vocabulário e à existência de anacronias, os alunos evidenciaram mais dificuldades na resolução dos itens agrupados nos parâmetros B e C e, tal como seria expectável, estas foram mais evidentes no desempenho dos alunos do $7 .^{\circ}$ ano. Contudo, esta dificuldade diminui à medida que se avança no nível de ensino, uma vez que, tal como é esperado, estes alunos adquiriram mais competências ao nível da compreensão e já são capazes de "descodificar, pelo contexto ou pelo recurso a obras lexicográficas diversas, o sentido de palavras ou expressões desconhecidas" (ME/DGIDC, p. 84, 2011) e de “captar sentidos implícitos" (idem, p. 85).

$\mathrm{Na}$ análise contrastiva entre ciclos de ensino foi possível concluir que, nos itens associados ao parâmetro A, os participantes de ambos os ciclos conseguiram atingir um desempenho satisfatório, embora este seja mais significativo no $3 .^{\circ} \mathrm{CEB}$. Ao contrário dos 
participantes deste ciclo de ensino, os pertencentes ao $2{ }^{\circ}$ CEB evidenciaram menos dificuldades na resolução dos exercícios associados ao parâmetro $\mathrm{C}$ e mais dificuldades no parâmetro B, ou seja, na interpretação de palavras, expressões ou segmentos textuais plurissignificativos ou implícitos, a partir do contexto. Os alunos em causa manifestaram dificuldades nos exercícios que remetiam para a compreensão de passagens com o recurso a uma linguagem menos objetiva e com sentidos pouco explícitos, remetendo para um reportório mais limitado no uso das infinitas possibilidades da língua. Os alunos surdos do $3 .^{\circ}$ ciclo obtiveram a maior percentagem de itens considerados inadequados nas respostas aos itens do parâmetro $\mathrm{C}$, evidenciando dificuldades na localização de informação em textos com passagens menos objetivas e, principalmente, com anacronias. Não obstante a apresentação estruturada dos exercícios de interpretação, os alunos destes níveis de ensino evidenciaram alguns constrangimentos na identificação da discrepância entre a ordem dos factos e o ritmo temporal da ação, neste caso, da analepse, e, como tal, manifestaram dificuldades na identificação de alguns elementos textuais, como: a continuidade temática, a progressão semântica, as cadeias de referência, as reiterações e substituições lexicais, os conetores interfrásicos e a ordenação correlativa dos tempos verbais.

Desta forma, deparamo-nos com um desempenho muito aproximado daquilo que é esperado no final do $2 .^{\circ}$ e 3..$^{\circ}$ ciclo e apraz-nos inferir que, em algumas das competências analisadas, o desempenho e as dificuldades destes alunos foram semelhantes ao esperado de um aluno ouvinte. Estes factos poderão ser um sinal de que as discrepâncias existentes entre os alunos ouvintes e os alunos com surdez começam a ser, gradualmente, esbatidas devido à ideia já instaurada nas comunidades educativas de que é necessário adotar estratégias e modelos específicos para mitigar as dificuldades destes alunos.

Para comprovar estas ilações, relembramos que os textos aplicados a estes alunos foram transcritos de manuais de Língua Portuguesa elaborados para esses níveis de ensino, ou seja, não foram selecionados a partir de materiais produzidos especificamente para alunos com surdez e, como tal, não obedeceram ao tipo de características consideradas habituais por estes alunos, nomeadamente no tipo de linguagem e na dimensão dos textos.

No entanto, não foi possível obter dados concretos sobre a influência do modelo educativo na aptidão de apreensão de competências essenciais à compreensão de textos narrativos, a partir da sua leitura. De facto, o desempenho dos alunos dos $2 .^{\circ}$ e $3 .^{\circ}$ ciclos que têm o Português como L1 e dos alunos com a LGP como L1 foi muito semelhante, neste processo de avaliação da competência da leitura.

Genericamente, o $3 .^{\circ}$ ciclo conseguiu obter uma percentagem mais satisfatória nos exercícios de inferência de conceitos a partir da análise e associação de elementos paratextuais, isto é, nos itens de pré-leitura, obtiveram uma elevada percentagem de respostas completamente inadequadas no parâmetro com maior sucesso no $2 .^{\circ}$ ciclo. Este facto comprova as dificuldades persistentes em manusear um texto com maiores dimensões, mesmo estando dividido em partes, de acordo com a sua estrutura interna.

Além disso, o número reduzido de respostas adequadas no parâmetro que exigia a apropriação de sentidos figurados, conotativos, polissémicos ou de mensagens implícitas poderá ter contribuído para as dificuldades sentidas na resolução das questões pertencentes ao parâmetro descrito anteriormente. Assim, não esquecendo que a prática faz o ofício, ou seja, que se aprende a ler lendo, consideramos que, também, seria benéfico a intensificação de tarefas que permitam "brincar" com as palavras e de exercícios orientados para a descodificação de expressões/vocábulos a partir do contexto. Será pertinente contribuir para a fomentação da ideia de que uma língua tem infinitas possibilidades e polivalências, através, por exemplo, de tarefas que permitam contextualizar o uso de um mesmo vocábulo em diferentes contextos e com diferentes significados.

Os diversos estudos efetuados no âmbito da surdez em contextos educativos sugerem a persistência de algumas inquietações, uma vez que estes alunos nem sempre têm o acesso atempado a uma língua de comunicação e devido à coexistência de modelos educativos distintos, embora se reconheça a importância do modelo de ensino bilingue.

Estas preocupações estiveram na origem do nosso trabalho e, como tal, esperamos fornecer algumas contribuições plausíveis para todos aqueles que trabalham com estes alunos e para futuros projetos de investigação.

\section{Referências bibliográficas}

Direção-Geral de Educação (DGE): legislação; dados relativos à Educação Especial. Consultado em 03 / 06 de Abril de 2012. http://www.dge.mec.pt/educacaoespecial

DRE (Diário da República Eletrónico): legislação. Consultado em 03 de Abril de 2012. http://dre.pt/

ME/DGIDC (2007). Programa Curricular de Língua Gestual Portuguesa: Educação Pré-Escolar e Ensino Básico. Lisboa: Direcção Geral de Inovação e de Desenvolvimento Curricular.

ME/DGIDC (2011), Programa de Português L2 para Alunos Surdos: Ensinos Básico e Secundário, Lisboa: Direcção Geral de Inovação e de Desenvolvimento Curricular.

Morais, A. M. \& Neves, I. P. (2007). Fazer Investigação usando uma abordagem metodológica mista. Departamento de Educação e Centro de Investigação em Educação: Faculdade de Ciências da Universidade de Lisboa.

Revista Diversidades, n. ${ }^{\circ} 25$ (2009). Serviço da Direcção Regional de Educação Especial e Reabilitação e Colaboradores Externos. Região Autónoma da Madeira.

Sim-Sim, I. (2005). A criança surda. Contributos para a sua Educação. Serviço de Educação e Bolsas. Fundação Calouste Gulbenkian.

Viana, F. L. \& Teixeira, M. M. (2002). Aprender a lerDa aprendizagem informal à aprendizagem formal. Lisboa: Edições ASA. 